Article

\title{
Evaluation of the Coordination of Structural Layers in the Design of Asphalt Pavement
}

\author{
Hao $\mathrm{Li}^{1,2}$, Naren Fang ${ }^{1, * \mathbb{D}}$, Xuancang Wang ${ }^{1, *} \mathbb{D}$, Chuanhai $\mathrm{Wu}^{3}$ and Yang Fang ${ }^{2}$ \\ 1 School of Highway Engineering, Chang'an University, Xi'an 710064, China; hao_li_20007@163.com \\ 2 Foshan Transportation Science and Technology Co. LTD, Foshan 528041, China; dfy8307@163.com \\ 3 Guangdong Hualu Communications Technology Co. LTD, Guangzhou 510420, China; \\ wutongshuxi_a@163.com \\ * $\quad$ Correspondence: 2017021044@chd.edu.cn (N.F.); wxc2005@chd.edu.cn (X.W.); Tel.: +86-029-8233-4836 (X.W.)
}

Received: 2 April 2020; Accepted: 30 April 2020; Published: 2 May 2020

\begin{abstract}
The purpose of asphalt pavement structural design is to get a materially-coordinated and structurally-durable product, and a pavement structure with good road performance by combining the structural layer materials reasonably. However, due to lack of a rational evaluation index on the parameter combinations of structural layer materials, the structural layer materials are poor in terms of coordination, have low efficiency, and the actual use period is much lower than the designed working life. Therefore, it is very important to conduct research evaluating the coordination of the structural layer materials. In this study, the sensitivity of mechanical parameters and equivalent envelope area are proposed as new indexes to evaluate the coordination of material design of asphalt pavement structure layers. Software is developed to calculate the equivalent envelope area that can quantitatively evaluate the coordination among different layers and visualize the mechanical transfer behavior of each structural layer. Based on the equivalent envelope area index, this study incorporates two new steps in the design of pavements, namely the structural form comparison and optimization, and proposes a new structural design process. Finally, the rationality and reliability of the equivalent envelope area index are verified by presenting fatigue life calculation and field verification in a test road. The results propose a clear evaluation index of the coordination of material design of each structural layer, which makes the structural design of the asphalt pavement more scientific and reasonable.
\end{abstract}

Keywords: road engineering; asphalt pavement; coordination evaluation; sensitivity; equivalent envelope area

\section{Introduction}

The purpose of optimal design of asphalt pavement structure is to determine a structural form with durable structure and good road performance by combining the parameter rationally of the structural layer materials. For this reason, the rational parameter combination of structural layer materials of the asphalt pavement is crucial for the road performance and structure durability. However, in the process of structural optimization design of asphalt pavement, in the absence of a rational evaluation index, the optimum coordination among the designed structural material parameters cannot be guaranteed, resulting in the low use efficiency of structural materials and a pavement service life far less than the design life; the direction of optimization is not clear, which easily leads to the uniformity and homogeneity of the pavement structure.

This paper is intended to improve the existing structural design methods through coordinated evaluation research of the asphalt pavement structural layer material setting, and to obtain the 
pavement structural form with a reasonable material combination, durable structure, and good road performance through the optimal combination of each structural layer materials.

Existing studies have focused on the structural design method, prediction model of fatigue life, structural type, material parameters, and other aspects of durable asphalt pavement. "AASHTO 2008" [1], "AI Law" [2], and "SHELL Law" [3] set the tensile strain of the bottom of the asphalt layer and the compressive strain of the top surface of the soil foundation as the design index, while the "Specifications for Design of Highway Asphalt Pavement (JTG D50-2006)" [4] set the deflection of the road surface and the tensile stress of key layers as the design index and also established the relationship between the design index under the load effect and the cumulative number of standard loads. The relation established by the above method only considered the load effect. Islam [5] developed a closed-form equation for calculating the temperature-induced fatigue damage. Using two types of rutting performance tests, i.e., CWTT (Cooper wheel tracking tests), and APA (asphalt pavement analyzer) tests, Hussan developed laboratory rutting prediction models; significant independent variables involved in the model are temperature, number of passes in the case of CWTT or number of cycles in the case of APA tests, bitumen penetration value, and Flakiness index of coarse aggregate fractions [6]. Bakhshi used FEM to simulate asphalt pavement rutting developed by the Hamburg wheel rut tester, then developed rutting prediction models to model the viscoelastic behavior of asphalt mixtures [7]. Kim employed the viscoelastic continuum damage (VECD) model to develop the C1-S1 curve, which is known as a single-characteristic curve of an asphalt mixture and is independent of loading types [8]. Al-Khateeb and Ghuzlan used an indirect tensile test and observed that increasing loading frequency and decreasing stress level increases fatigue life of asphalt mixtures [9]. Mansourkhaki studied the effects of loading waveforms, load duration, rest period, and stress level on the fatigue life of hot mix asphalt (HMA) specimens using the indirect tensile test [10]. Zhu looked into the fatigue property of aged asphalt mixtures as well as the comparison of the fatigue property conducted by both ageing methods, and concluded that the actual life-span of pavement is often shorter than the designed one [11]. Pais presented a study to evaluate the number of tests to assess the fatigue resistance of asphalt mixtures, and through the four-point bending technique evaluated the fatigue resistance dispersion to identify the number of tests to define a fatigue law [12]. Montazeri examined the influence of mix proportions, specifically asphalt and air void contents, on fatigue behavior of asphalt beam specimens in the laboratory tested with a four-point bending method of loading [13]. Yizhuang evaluated RAP mixtures at both the material level and the structural level using mechanistic models and observed that the performance of RAP mixtures depended on the mixture design and pavement structure [14].

Specifications for Design of Highway Asphalt Pavement (JTG D50-2006) [4] stipulate that the modulus ratio between the base course and the asphalt surface course of semi-rigid base asphalt pavement should be between 1.5 and 3 , the modulus ratio between the base course and the sub-base should not be greater than 3.0, and the modulus ratio between the sub-base and the soil base should be between 2.5 and 12.5. Zhang measured the modulus ratio of key layers by falling weight deflectometer (FWD) through mechanical analysis and practical project tracking observation, and suggested that the modulus ratio of flexible base and semi-rigid base to surface layer should be 8-10 and 1.5-3, respectively $[15,16]$. Zhen established a fatigue equation of asphalt mixtures through a fatigue test, which was characterized by the true stress ratio, and proposed a new idea of asphalt pavement structure design that would increase design life from top to bottom and a new idea of durable asphalt pavement structure design, and suggested that the design life of the middle and upper layer, the lower layer, and the base layer should be 10-15 years, 20-30 years, and 40-60 years, respectively [17].

According to the design index of California, the bending strain of asphalt mixture layers is less than 700 and the compressive strain of the top surface of soil foundation is less than 200 when the uniaxial load is $80 \mathrm{kN}$ [18]. The design of Illinois transportation department requires that the flexural strain of the asphalt mixture base should be less than $600 \mu \varepsilon$ [19]. Cui suggested control indexes suitable for the structural design of durable pavement in China; the tensile strain of the bottom layer of 
asphalt was not more than $120 \times 10^{-6}$, and the compressive strain of the top surface of soil foundation was not more than $280 \times 10^{-6}$ [20].

Meng proposed a reasonable combination form of asphalt pavement structure, and systematically studied the structural design method of asphalt pavement, design parameters of graded gravel material, and construction technology and construction quality detection methods of graded gravel [21]. In view of the defects of the current fatigue design method of asphalt pavement in China, Liu found that semi-rigid base asphalt pavement can meet the requirements of durable pavement through the reasonable matching of the service life of each structural layer, and through the optimization of methods such as replacing materials, changing thickness, and changing layers [22]. Lv proposed a pavement structure design method such that the deflection of the asphalt pavement structure layer matches the fatigue life of the tensile stress index of the bottom layer [23]. Zhuang proposed a design process and steps of the flexible base asphalt pavement, and recommended the appropriate thickness of the structural layer of the granular base asphalt pavement under heavy load traffic [24].

Although scholars worldwide have done a lot of studies, there are still the following problems: (1) Through theoretical analysis or laboratory tests, the relationship model between different design indexes and the cumulative number of standard loads has been established, but the designed indexes mostly consider the failure behavior of each layer of materials separately, and do not evaluate the coordinated relationship between layers of a pavement structure. (2) The key steps of the existing structural design process are to calculate the cumulative number of standard loads by design indexes, and repeatedly adjust the material parameters until the cumulative standard loads meet the design requirements. However, the coordination between the material parameters of the designed structure cannot be guaranteed, so the design result is only an optimal solution for a part of but not for an overall situation. (3) The recommended range of the modulus ratio between structural layers is too large, the structure arrangement and combination forms are too numerous and difficult to operate, and the results of the rational combination of structures can be used only for the specified structural form; no general indicators or methods are proposed. Therefore, existing research lacks an answer to the question of how to design the material parameters of each structural layer of asphalt pavement structure by considering each layer as a component of a pavement structure.

This paper proposes the design of an asphalt pavement structure by considering each structural layer as a component of the pavement structure and by analyzing the coordination between the layers. The major findings of this article are summarized as follows: (1) Indexes are proposed for the sensitivity and equivalent envelope area to qualitatively and quantitatively evaluate the coordination of the structural layers. The evaluation process is visualized by using stress transfer path and transfer path envelope diagrams. (2) Based on the equivalent envelope area, software is developed for the structural optimization design. (3) Based on the equivalent envelope area index, an existing design process is improved by adding steps of structural scheme comparison and structural optimization. (4) The feasibility and validity of the equivalent envelope area index are verified by fatigue life calculation and road tests.

\section{Calculation Details}

\subsection{Computational Model}

The theory of the elastic layered continuous system was adopted. The commercial software BISAR 3.0 was used for simulation calculation. The material of each layer was assumed to be an isotropic linear elastomer that was continuous in the horizontal direction, the interface between layers was assumed as completely continuous, and the soil foundation was assumed to be a semi-infinite foundation or a uniform horizontal layer on a half-space.

Two forms of uniform load were adopted, i.e., double circle and single circle. The uniform load radius of single circle was $15 \mathrm{~cm}$, and the load pressure was $0.707 \mathrm{MPa}$. The uniform load radius of 
double circles was $10.65 \mathrm{~cm}$, the distance between centers of load circles was $31.95 \mathrm{~cm}$, and the load pressure was $0.707 \mathrm{MPa}$. The simplified pavement models under two load forms are shown in Figure 1.

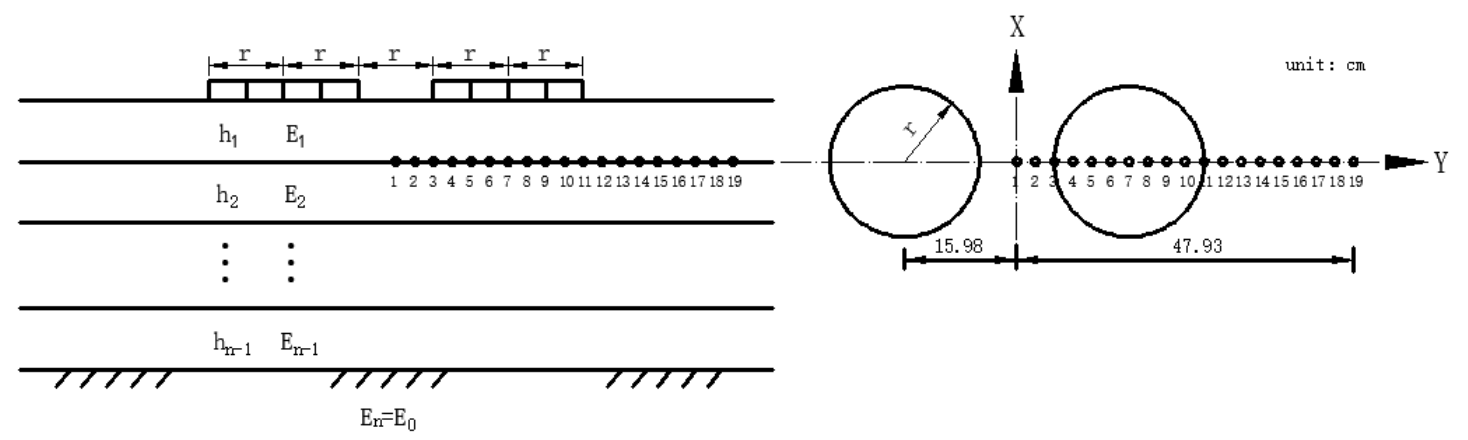

(a) Double circle load

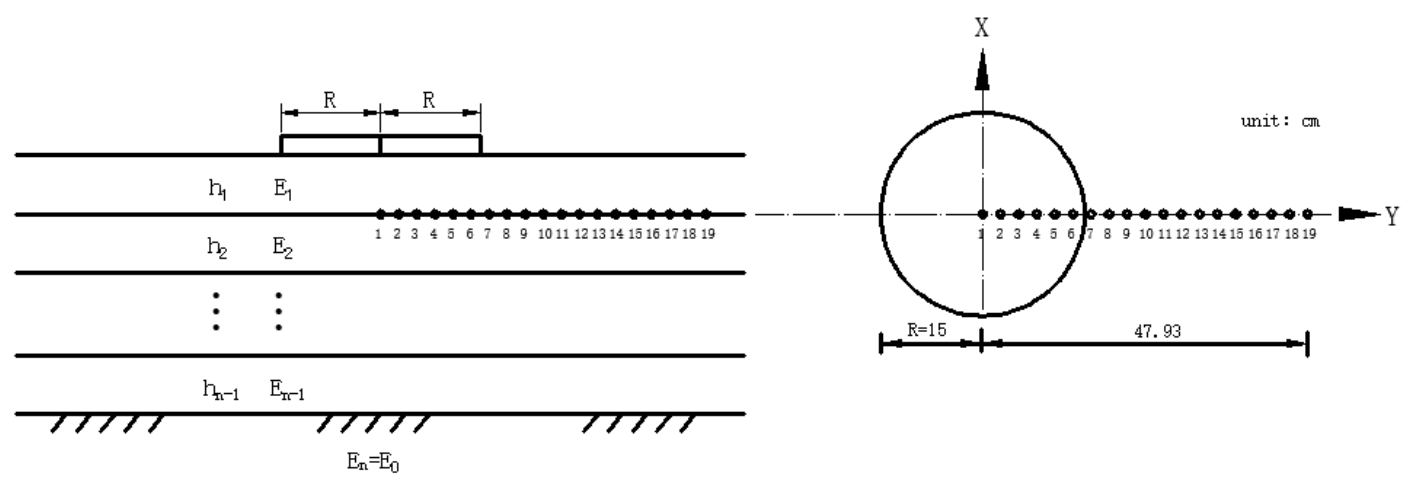

(b) Single circle load

Figure 1. Simplified model of pavement structures and the selected calculation points.

\subsection{Calculation Parameter}

In order to study the coordination of the pavement structure, three different structures of asphalt pavement were paved on the Yunluo Expressway in Guangdong Province in 2012, namely, reinforced cement stabilized base asphalt pavement structure, roller compacted concrete base asphalt pavement structure, and inverted base asphalt pavement structure. The three structures are hereinafter referred to as structure I, structure II, and structure III, respectively. The structural types are shown in Table 1, and the corresponding material parameters are shown in Table 2.

Table 1. Pavement types.

\begin{tabular}{|c|c|c|c|}
\hline Layer & Structure I & Structure II & Structure III \\
\hline \multirow[b]{2}{*}{ Surface } & \multicolumn{2}{|c|}{$5 \mathrm{~cm}$ modified asphalt $\mathrm{AC}-16$} & $4 \mathrm{~cm}$ modified asphalt $\mathrm{AC}-16$ \\
\hline & \multicolumn{2}{|c|}{-} & $6 \mathrm{~cm}$ modified asphalt AC-20 \\
\hline \multirow{3}{*}{ Base } & $\begin{array}{l}19 \mathrm{~cm} \text { reinforced cement stabilized } \\
\text { macadam (strength }>6 \mathrm{Mpa} \text { ) }\end{array}$ & $\begin{array}{l}24 \mathrm{~cm} \text { roller compacted concrete } \\
(\text { strength }>12 \mathrm{MPa})\end{array}$ & $\begin{array}{c}20 \mathrm{~cm} \text { cement stabilized macadam } \\
\text { (strength } 3-5 \mathrm{MPa} \text { ) }\end{array}$ \\
\hline & $\begin{array}{l}19 \mathrm{~cm} \text { cement stabilized macadam } \\
\text { (strength 3-5 Mpa) }\end{array}$ & $\begin{array}{l}19 \mathrm{~cm} \text { cement stabilized macadam } \\
\text { (strength } 3-5 \mathrm{MPa} \text { ) }\end{array}$ & $20 \mathrm{~cm}$ graded aggregate \\
\hline & $\begin{array}{l}19 \mathrm{~cm} \text { cement stabilized macadam } \\
\text { (strength 3-5 Mpa) }\end{array}$ & $20 \mathrm{~cm}$ graded aggregate & $\begin{array}{c}20 \mathrm{~cm} \text { cement stabilized macadam } \\
\text { (strength 3-5 MPa) }\end{array}$ \\
\hline
\end{tabular}


Table 2. Design parameters of pavement materials for each layer (unit: MPa).

\begin{tabular}{cccc}
\hline Layer & Structure I & Structure II & Structure III \\
\hline \multirow{3}{*}{ Surface } & 1800 & 1800 & 1800 \\
& $/$ & $/$ & 1600 \\
& 3500 & 3500 & 1500 \\
\hline \multirow{2}{*}{ Base } & 6000 & 18,000 & 3600 \\
& 6000 & 3600 & 3600 \\
& 3600 & 3600 & 350 \\
Subgrade & 3600 & 350 & 3600 \\
\hline
\end{tabular}

As seen Table 1, the design strength (7-day unconfined compressive strength) of cement stabilized macadam in structure II and III was 3-5 MPa, so the modulus, as seen in Table 2, was taken as $3600 \mathrm{MPa}$. However, for structure I, the strength of cement stabilized macadam of the upper and lower base was greater than $6 \mathrm{MPa}$, and hence, the modulus was taken as $6000 \mathrm{MPa}$. In addition, Poisson's ratio was taken as $0.35,0.25,0.25,0.4$, and 0.4 , respectively, for the asphalt mixture, cement stabilized macadam, roller compacted concrete, graded aggregate, and subgrade. The material parameters shown in Table 2 were adopted from $[25,26]$.

For consistency, the thickness of the lower surface layer, base layer, and sub-base layer under structure I were taken as $0.13 \mathrm{~m}, 0.51 \mathrm{~m}$, and $0.89 \mathrm{~m}$, respectively. Respective thicknesses for structure II were taken as $0.13 \mathrm{~m}, 0.37 \mathrm{~m}$, and $0.75 \mathrm{~m}$. Similarly, for structure III, respective thicknesses were taken as $0.18 \mathrm{~m}, 0.58 \mathrm{~m}$, and $0.98 \mathrm{~m}$. Among them, the graded aggregate layer in structure II was a functional layer and was not treated as a structural layer.

\subsection{Stress Calculation Points}

The directions $\mathrm{X}, \mathrm{Y}$, and $\mathrm{Z}$ were considered as driving direction, cross section direction, and depth direction, respectively. According to the most unfavorable stress principle, under the uniform load of double circles, the section along the cross-section through the wheel gap center (hereinafter referred to as $Y Z$ section) was selected for research, and 30 points were selected in this plane for stress calculations.

The Y-value of the calculation points of the pavement structure are shown in Table 3 . The range of Y-value for the first 19 points was $0-0.4793 \mathrm{~m}$, and the value interval was $0.0266 \mathrm{~m}$. The range of values for the last 11 points was $0.6-3.6 \mathrm{~m}$, and the value interval was $0.3 \mathrm{~m}$. Due to the limitation of space, only 1-19 points are shown in Figure 1.

Table 3. Y-values of the selected calculation points of the pavement structure.

\begin{tabular}{ccccccccccc}
\hline Number & $\mathbf{1}$ & $\mathbf{2}$ & $\mathbf{3}$ & $\mathbf{4}$ & $\mathbf{5}$ & $\mathbf{6}$ & $\mathbf{7}$ & $\mathbf{8}$ & $\mathbf{9}$ & $\mathbf{1 0}$ \\
\hline Coordinate $/ \mathrm{m}$ & 0 & 0.0266 & 0.0533 & 0.0799 & 0.1065 & 0.1331 & 0.1598 & 0.1864 & 0.2130 & 0.2397 \\
\hline Number & $\mathbf{1 1}$ & $\mathbf{1 2}$ & $\mathbf{1 3}$ & $\mathbf{1 4}$ & $\mathbf{1 5}$ & $\mathbf{1 6}$ & $\mathbf{1 7}$ & $\mathbf{1 8}$ & $\mathbf{1 9}$ & $\mathbf{2 0}$ \\
\hline Coordinate $/ \mathrm{m}$ & 0.2663 & 0.2929 & 0.3195 & 0.3461 & 0.3728 & 0.3994 & 0.4260 & 0.4526 & 0.4793 & 0.6 \\
\hline Number & $\mathbf{2 1}$ & $\mathbf{2 2}$ & $\mathbf{2 3}$ & $\mathbf{2 4}$ & $\mathbf{2 5}$ & $\mathbf{2 6}$ & $\mathbf{2 7}$ & $\mathbf{2 8}$ & $\mathbf{2 9}$ & $\mathbf{3 0}$ \\
\hline Coordinate $/ \mathrm{m}$ & 0.9 & 1.2 & 1.5 & 1.8 & 2.1 & 2.4 & 2.7 & 3.0 & 3.3 & 3.6 \\
\hline
\end{tabular}

For the double circle uniform load, point 7 lay directly below the center of the double circle load, and point 11 was the outermost point of the circle under the double circle load. For the uniform load of single circle, point 1 lay directly below the center of single circle load.

\section{Analysis of Mechanical Response Index}

\subsection{Deflection Response Analysis}

The deflection values of the road surface were taken at 30 points for the three structures. The deflection of the road surface for the three structures is shown in Figure 2. The deflection values 
for the three structures were compared and analyzed to derive the deflection sensitivity distribution laws of the three structures, as shown in Figure 2.

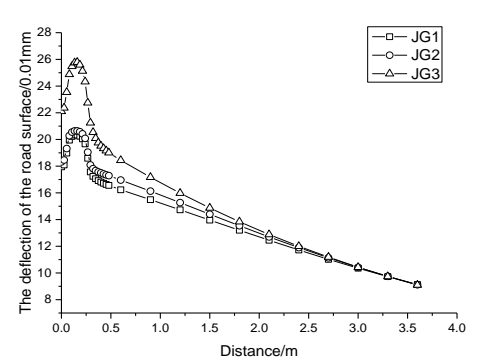

(a) Double circle load

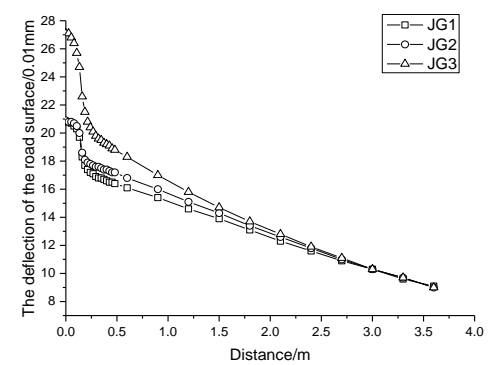

(b) Single circle load

Figure 2. Road deflection of three structures.

It can be seen from Figure 2 that under the double circle load, the maximum deflection values of structure I, structure II, and structure III were, respectively, $20.3(0.01 \mathrm{~mm}), 20.1(0.01 \mathrm{~mm})$, and 25.8 $(0.01 \mathrm{~mm})$, and the order of deflection was structure II < structure I < structure III. The maximum deflection value appeared at point 7 , which was directly below the center of the double circle load. Under the single circle load, the maximum deflection values of structure I, structure II, and structure III were, respectively, $20.8(0.01 \mathrm{~mm}), 20.9(0.01 \mathrm{~mm})$, and $27.1(0.01 \mathrm{~mm})$, and the order of deflection was structure I < structure II < structure III. The maximum deflection value appeared at point 1 , which was directly below the center of the single circle load.

Under the double circle load, the distance was $0.6 \mathrm{~m}$ when structures 1 and 2 had the largest difference in deflection values. The deflection values of structure I and structure II were $16.23(0.01 \mathrm{~mm})$ and $16.59(0.01 \mathrm{~mm})$, respectively, with a difference of $100 \% \times(16.59-16.23) / 16.59=2.2 \%$. Under the single circle load, the distance was $0.479 \mathrm{~m}$ when structures 1 and 2 had the largest difference in deflection values. The deflection values of structure I and structure II were $16.5(0.01 \mathrm{~mm})$ and 17.3 $(0.01 \mathrm{~mm})$, respectively, with a difference of $100 \% \times(17.3-16.5) / 17.3=4.4 \%$. From the evaluation of pavement surface deflection, the rigidity of structure I and structure II was close, but was better compared to structure III.

\subsection{Stress Response Analysis}

The stress values at 30 points of key layers were extracted, and the distribution of the stress of the key layers of three structures were compared and analyzed, as shown in Figure 3. The maximum tensile stress of key layers under the uniform load of double circles and single circles is shown in Tables 4 and 5.

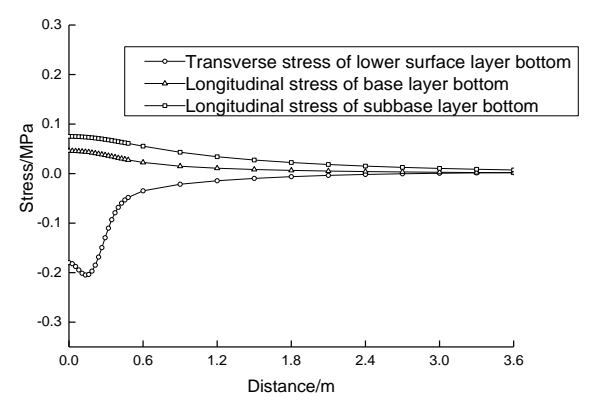

(a)

Figure 3. Cont. 


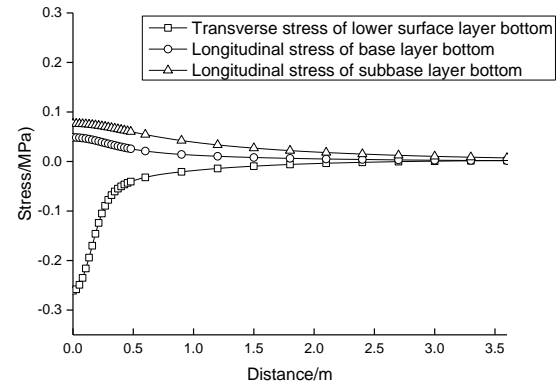

(b)

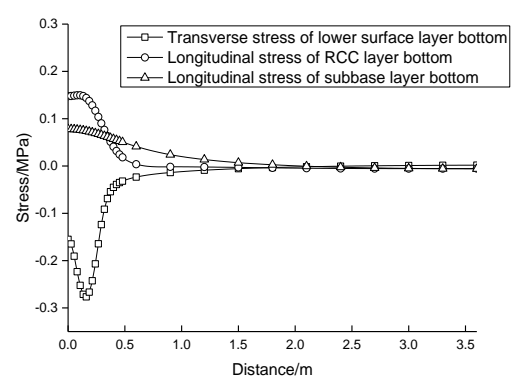

(c)

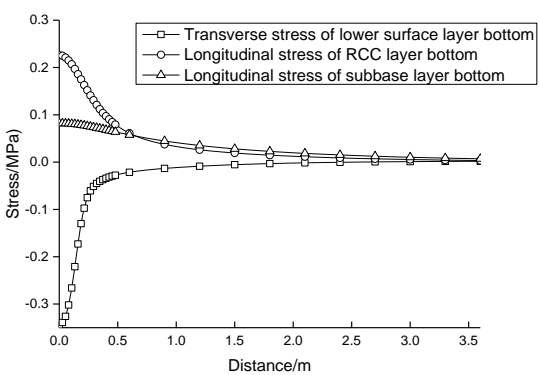

(d)

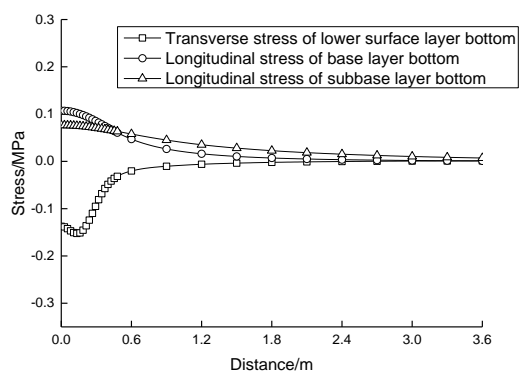

(e)

Figure 3. Cont. 


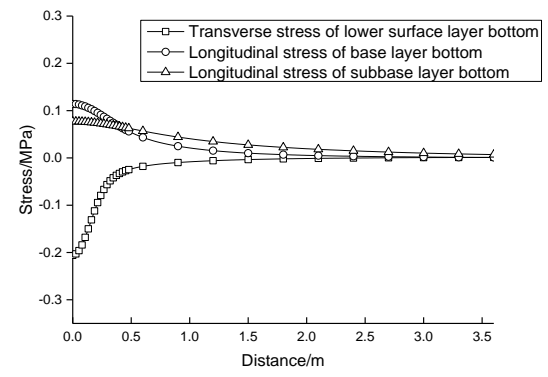

(f)

Figure 3. Stress variation diagram of key layers of three structures: (a) structure I under the double circle load; (b) structure I under the single circle load; (c) structure II under the double circle load; (d) structure II under the single circle load; (e) structure III under the double circle load; (f) structure III under the single circle load.

Table 4. Maximum tensile stress of key layers under the uniform load of double circle (unit: MPa).

\begin{tabular}{cccc}
\hline Layer & Structure I & Structure II & Structure III \\
\hline Lower surface layer bottom & -0.2048 & -0.2766 & -0.1524 \\
\hline Base layer bottom & 0.0459 & 0.1987 & 0.1072 \\
\hline Sub-base layer bottom & 0.0751 & 0.08095 & 0.0764 \\
\hline
\end{tabular}

Table 5. Maximum tensile stress of key layers under the uniform load of single circle (unit: MPa).

\begin{tabular}{cccc}
\hline Layer & Structure I & Structure II & Structure III \\
\hline Lower surface layer bottom & -0.261 & -0.3436 & -0.2057 \\
\hline Base layer bottom & 0.0486 & 0.2261 & 0.1143 \\
\hline Sub-base layer bottom & 0.07634 & 0.08221 & 0.0771 \\
\hline
\end{tabular}

Under the uniform load of the double circle, the maximum compressive stress of the lower surface layer of structure I, II, and III was $0.2048 \mathrm{MPa}, 0.2766 \mathrm{MPa}$, and $0.1524 \mathrm{MPa}$, respectively, with the order of structure II > structure I > structure III. The maximum tensile stress of the base layer was $0.0459 \mathrm{MPa}$, $0.1987 \mathrm{MPa}$, and $0.1072 \mathrm{MPa}$, respectively, with the order of structure II > structure III > structure I. The maximum tensile stress of the sub-base layer was $0.07510 \mathrm{MPa}, 0.08095 \mathrm{MPa}$, and $0.07640 \mathrm{MPa}$, respectively, and the order was structure II $>$ structure III $>$ structure I.

Under the uniform load of the single circle, the maximum compressive stress of the lower surface layer of structure I, II, and III was $0.261 \mathrm{MPa}, 0.3436 \mathrm{MPa}$, and $0.2057 \mathrm{MPa}$, respectively, with the order of structure II $>$ structure I $>$ structure III. The maximum tensile stress of the base layer was $0.04860 \mathrm{MPa}, 0.22610 \mathrm{MPa}$, and $0.11430 \mathrm{MPa}$, respectively, with the order of structure II > structure III > structure I. The maximum tensile stress of the sub-base layer was $0.07634 \mathrm{MPa}, 0.08221 \mathrm{MPa}$, and $0.07710 \mathrm{MPa}$, respectively, with the order of structure II $>$ structure III $>$ structure I.

Under the uniform load of single circle and double circles, the stress sequence of each key layer was the same. The lower surface layer was always subjected to compressive stress. Nevertheless, in the Specifications for Design of Highway Asphalt Pavement (JTG D50-2006), the fatigue cracking of the lower surface layer is controlled by tensile stress.

Under the uniform load of the double circle and single circle, with an increase in distance, the stress of different layers was almost identical, indicating that the stress value at a distance could not serve as an evaluation index, and hence, the stress value after $2 \mathrm{~m}$ could be ignored. 


\section{Evaluation of the Coordination of Three Types of Asphalt Pavement Structures}

\subsection{Definition}

The sensitivity is the ratio of the mechanical response value (including stress and defection) of a point in the $Y$ direction of the $Y Z$ section to the maximum mechanical response value in the $Y$ direction of the section, and is calculated as in Equation (1). This study mainly analyzes stress sensitivity and deflection sensitivity.

$$
\omega_{i, h}=\frac{\delta_{i, h}}{\delta_{\max , h}} \times 100 \%
$$

In Equation (1), $\omega_{i, h}$ is the mechanical index sensitivity of point $i$ at depth $h ; \omega_{i, h}$ is dimensionless; $h$ is the depth along the $Z$ direction and the unit is $m ; \delta_{i, h}$ is the mechanical response value of point $i$ at depth $h$; and $\delta_{\max , \mathrm{h}}$ is the maximum mechanical response value of all points at depth $\mathrm{h}$.

Example 1. Calculation of the deflection sensitivity of point 20 in the road surface $(Z=0 \mathrm{~m})$.

Given data: $\delta_{20,0}=16.23$ (deflection, $0.01 \mathrm{~mm}$ ), $\delta_{\max , 0}=\delta_{7,0}=17.95$ (deflection, $0.01 \mathrm{~mm}$ )

$$
\omega_{i, h}=\frac{\delta_{i, h}}{\delta_{\max , \mathrm{h}}} \times 100 \%=\omega_{20,0}=\frac{\delta_{20,0}}{\delta_{\max , 0}} \times 100 \%=\frac{16.23}{17.95} \times 100 \%=90.4 \%
$$

Therefore, the deflection sensitivity of point 20 in the road surface is $90.4 \%$.

Example 2. Calculation of the transverse stress sensitivity of point 15 in the bottom of the lower surface layer $(Z=0.13 \mathrm{~m})$.

$$
\omega_{i, \mathrm{~h}}=\frac{\delta_{\mathrm{i}, \mathrm{h}}}{\delta_{\max , \mathrm{h}}} \times 100 \%=\omega_{20,0}=\frac{\delta_{15,0.13}}{\delta_{\max , 0.13}} \times 100 \%=\frac{-0.05427}{-0.2766} \times 100 \%=11.5 \%
$$

Given data: $\delta_{15,0.13}=-0.05427$ (stress, MPa), $\delta_{\max , 0.13}=\delta_{7,0.13}=-0.2766$ (stress, MPa).

Therefore, the transverse stress sensitivity of point 15 in the bottom of the lower surface layer is $11.5 \%$.

According to the definition: (1) at point imax of the maximum mechanical response value, $\omega_{\text {imax }}=100 \%$, and at point i $\infty$ at infinity, $\omega_{\infty}=0$; (2) for different types of pavement structure, the greater the sensitivity of deflection, the stronger is the rigidity of pavement structure; and (3) the greater the stress sensitivity, the more uniform is the stress distribution, and the higher is the material utilization efficiency.

\subsection{Software Development and Use}

In order to quantify the coordination of structural layers of an asphalt pavement, Intelligent Analysis Software V1.0 for mechanical properties of asphalt pavement (hereinafter referred to as the analysis software) was developed. The software was used to quantitatively evaluate the coordination of three asphalt pavement structural designs.

The analysis software is based on Net framework, Bisar3.0, Excel, and AutoCAD. Through parameter inputs, the mechanical response of different points in the target layer could be extracted. Based on the sensitivity threshold, the software generated the envelope area and the graph of the stress transfer path as outputs.

The main steps of calculation by using the software were as follows:

(1) Input the load, pavement structure thickness, and material parameters; input the points (locations) of the mechanical index to be extracted from the target layer, and complete the calculation; 
(2) Input the mechanical calculation results into Excel, and calculate the sensitivity of mechanical indexes;

(3) Determine the point coordinates of the asphalt layer, base layer, and sub-base layer according to the sensitivity threshold. In AutoCAD, an envelope diagram of the transfer path was drawn according to the thickness of the structural layer and the point coordinates. The envelope areas of the asphalt layer, base layer, and sub-base layer were generated as the output of the software.

The boundary point of the road surface $(z=0)$ was the intersection of the outermost side of the double circle load and the road surface, and the scale of the AutoCAD output drawing was 1:1. The drawing obtained by connecting the boundary point, the position of points at the bottom of each key layer, and the boundary line between the layers was defined as the transfer path envelope diagram. Two sides of the envelope were defined as the stress transfer path.

The mechanics of the transfer path envelope diagram were interpreted such that under the wheel load, the effective workspace of the pavement structural layer was determined based on the sensitivity threshold. The stress transfer path was the path of the envelope diagram along the thickness direction of the structural layer. The path characterized the stress distribution of the structural layer under the wheel load. The stress transfer path visualized the stress transfer behavior and clearly presented the route of stress transfer and the state of stress distribution in the pavement structure.

\subsection{The Rules Analysis of Sensitivity}

\subsubsection{The Rules of Deflection Sensitivity}

By conducting the steps (1) and (2) of the analysis software, the deflection sensitivity within the range of $0-3.6 \mathrm{~m}$ under the single and double circular loads was calculated, respectively, as shown in Figure 4.

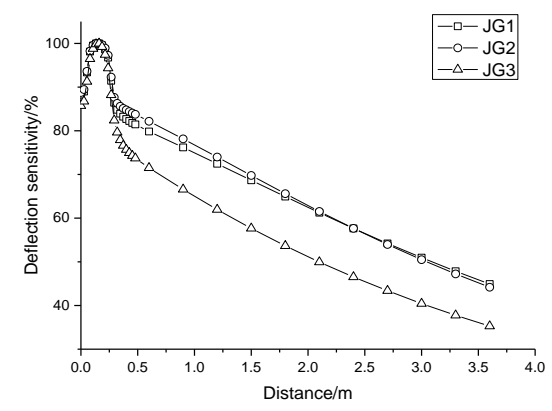

(a) Double circle load

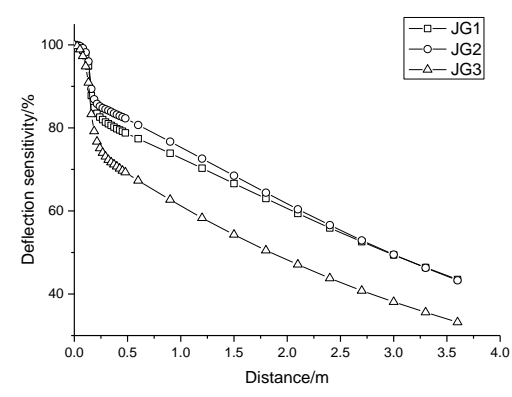

(b) Single circle load

Figure 4. Deflection sensitivity of three structures. 
Comparative analysis of deflection sensitivity of three structures according to Figure 4 revealed the following points: (1) Under the double circle load, the order of deflection sensitivity was structure II $>$ structure I > structure III for points 1-26 (i.e., transverse distance $0-2.4 \mathrm{~m}$ ), and structure II > structure III for points 27-30 (i.e., transverse distance 2.7-3.6 m). (2) Under the single circle load, the order of deflection sensitivity was structure II $>$ structure I $>$ structure III for point 1-28 (i.e., transverse distance 0-3 m), and structure I > structure II > structure III for point 29-30 (i.e., transverse distance 3-3.6 m).

The three structures were also compared for the deflection and deflection sensitivity curves. The comparison revealed the following points: (1) Near the load, the deflection values were quite different, but the deflection sensitivity values were slightly different. (2) With an increase in distance, the deflection curves of different pavement structures came closer and almost overlapped, which indicated that the deflection value at a point far away from the load was less sensitive to the type of pavement structure. Therefore, the deflection and deflection sensitivity far away from the load were not considered in this study, and hence, it was concluded that the order of deflection sensitivity of three pavement structures was structure II $>$ structure I $>$ structure III. According to the meaning of deflection sensitivity as in Equation (1), the ranking results of the structural rigidity of the three structures were the same as that of the deflection under the uniform load of double circles, but not the same as that under the uniform load of single circle. (3) With an increase in distance, the sensitivity curves of structure I and structure II were almost identical (Figure 4), but were different from the sensitivity curve of structure III, which showed that the rigidity of structure I and structure II was relatively close and significantly larger than that of structure III. This observation is consistent with the conclusion of the previous analysis of deflection.

This analysis showed that the deflection value cannot serve as an evaluation index because different conclusions could be drawn with different loading forms. For example, for structure I and structure II in this paper, the order of the maximum deflection value under the uniform load of double circle and single circle was just the opposite. However, the sensitivity of deflection was not affected by the load form, and the conclusion of uniform load form of the single circle and double circle was consistent with that of the uniform load form of the double circle required by the specifications. Furthermore, since the deflection value further from the load was similar for different structures, the deflection value evaluation, which was based on the maximum deflection value of a single point, would present limited information. However, the deflection sensitivity was based on a number of sensitivity values on a line in the $Y$ direction of $Y Z$ section, and the curve formed by the sensitivity could distinguish the rigidity of different structural types.

\subsubsection{The Rules of Stress Sensitivity}

Conducting steps (1) and (2) of the analysis software, the stress sensitivity of the lower surface layer bottom, the lower base layer bottom, and the sub-base layer bottom under three structures within the range of 0-3.6 m under the single and double circular loads was calculated, respectively, as shown in Figures 5-7.
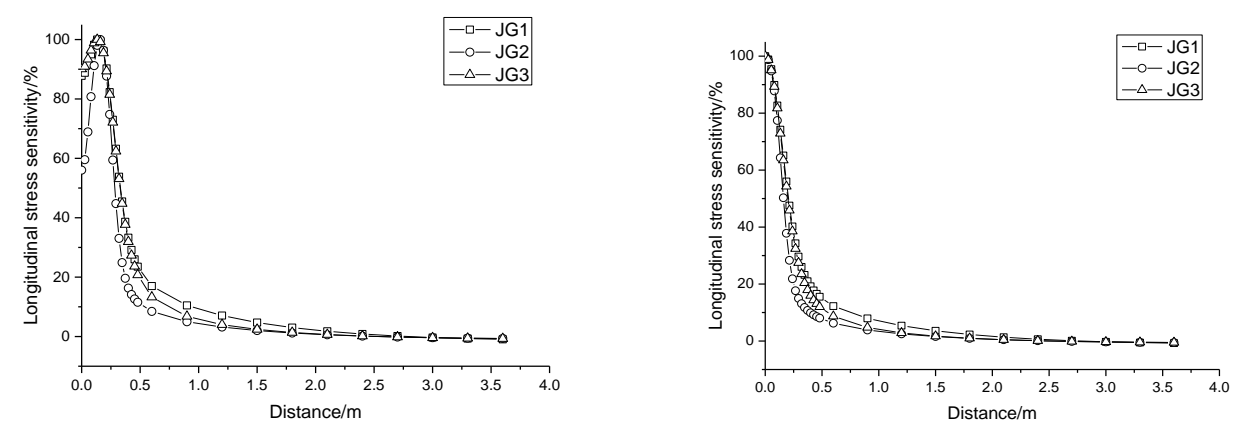

Figure 5. Transverse stress sensitivity of the lower surface layer bottom of three structures (unit: \%). 

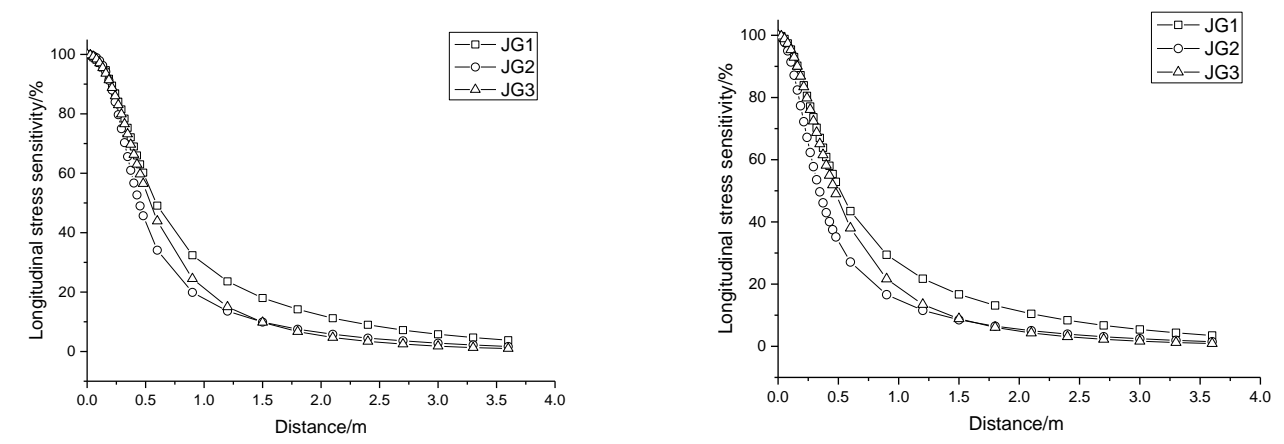

Figure 6. Longitudinal stress sensitivity of the base layer bottom of three structures (unit: \%).
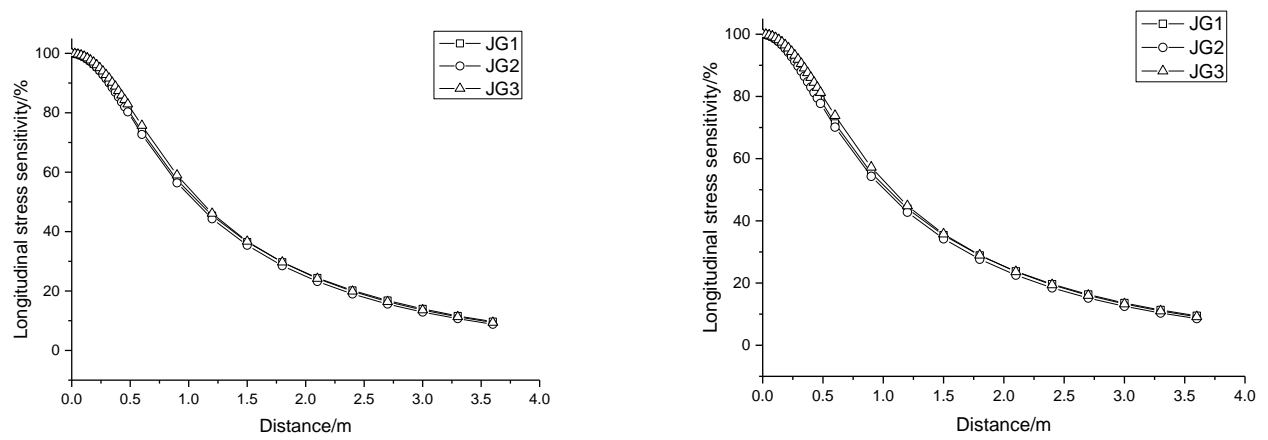

Figure 7. Longitudinal stress sensitivity of the sub-base layer bottom of three structures (unit: \%).

According to the definition of stress sensitivity and the rules of deflection sensitivity in Section 4.3, the range of stress sensitivity under the uniform load of double circles and single circle was $0.1864-2 \mathrm{~m}$ and $0-2 \mathrm{~m}$, respectively.

In the selected range, under the double circle and single circle loads, sensitivity of the transverse stress at the lower surface layer was ranked as structure I > structure III > structure II, the longitudinal stress at the base layer was ranked as structure I > structure III > structure II, and the longitudinal stress at the sub-base layer was ranked as structure III $>$ structure I $>$ structure II.

Large differences were observed in the ranking results of stress and stress sensitivity of each layer. This was attributed to the fact that the maximum stress of a single point at the bottom of the structural layer represented the most unfavorable mechanical state of the structural layer under the load, and the starting point focused on the structure. On the other hand, the stress sensitivity at the bottom of the layer represented the feedback mechanism of the material of each structural layer after the structure was stressed, and focused on the material.

As shown in Figures 5-7, comparing the sensitivity of the three road structures at the same distance as the distance increased, the difference in sensitivity of the three road structures increased first and then decreased. Under the double circle load, the maximum difference in the transverse stress of the lower surface layer, the longitudinal stress of the base layer and the longitudinal stress sensitivity of the sub-base layer was $20.8 \%, 15.0 \%$, and $3.0 \%$, respectively, and the corresponding distance was $0.3195 \mathrm{~m}, 0.6 \mathrm{~m}$, and $0.6 \mathrm{~m}$, respectively. Under the single circle load, the maximum difference in the transverse stress of the lower surface layer, the longitudinal stress of the base layer, and the longitudinal stress sensitivity of the sub-base layer was $19.2 \%, 17.9 \%$, and $3.7 \%$, respectively, and the corresponding distance was $0.213 \mathrm{~m}, 0.426 \mathrm{~m}$, and $0.6 \mathrm{~m}$, respectively. The difference in stress sensitivity was mainly observed in the surface layer and base layer. This observation is consistent with the understanding that semi-rigid base acts as the main bearing layer. Therefore, the stress sensitivity index was observed as a suitable index for evaluating the mechanical performance of a pavement structure.

The stress sensitivity of structure I was greater than that of structure II, which indicated that the utilization efficiency of the asphalt layer and semi-rigid sub-base material of structure I was better 
than that of structure II due to the difference in construction method, namely, setting of reinforced semi-rigid base material and roller compacted concrete base material. The semi-rigid sub-base materials of structure I and structure III were approximately identical, with thicknesses of $19 \mathrm{~cm}$ and $20 \mathrm{~cm}$, respectively. The stress sensitivity of structure III was greater than that of structure I, which was contrary to the conclusion based on stress sensitivity of the lower layer and the base layer. This contrast might have been related to the thickness.

Comparison of deflection sensitivity and stress sensitivity indicates that the deflection sensitivity can evaluate the rigidity of the entire structure, and the stress sensitivity can evaluate the stress distribution uniformity and material utilization efficiency of each layer. However, the sensitivity index can only be qualitatively analyzed, and the degree to which the results of each layer are inconsistent may be related to the thickness, which is further analyzed in the following section.

\subsection{Analysis of Evaluation Results}

Considering the influence of different sensitivity threshold values on the evaluation results, five different thresholds of $50 \%, 40 \%, 30 \%, 20 \%$, and $10 \%$ were selected for the stress sensitivity of the key layers. The coordinates of the bottom of each key layer under different thresholds of three pavement structures were extracted by using the analysis software, as shown in Table 6 . The transfer path envelope diagram of each structural layer was obtained and its area was calculated by the analysis software. The envelope diagram is shown in Figure 8 and the envelope area is shown in Table 7.

Table 6. Threshold distance of each layer (unit: $\mathrm{m}$ ).

\begin{tabular}{|c|c|c|c|c|c|c|}
\hline Structural Type & Layer & $50 \%$ & $40 \%$ & $30 \%$ & $20 \%$ & $10 \%$ \\
\hline \multirow{3}{*}{ Structure I } & Lower surface layer bottom $(0.13 \mathrm{~m})$ & 0.331 & 0.367 & 0.420 & 0.532 & 0.935 \\
\hline & Lower base layer bottom $(0.51 \mathrm{~m})$ & 0.589 & 0.736 & 0.966 & 1.381 & 2.257 \\
\hline & Sub-base layer bottom $(0.89 \mathrm{~m})$ & 1.076 & 1.374 & 1.790 & 2.419 & 3.558 \\
\hline \multirow{3}{*}{ Structure II } & Lower surface layer bottom $(0.13 \mathrm{~m})$ & 0.283 & 0.303 & 0.328 & 0.370 & 0.529 \\
\hline & Lower base layer bottom $(0.37 \mathrm{~m})$ & 0.446 & 0.531 & 0.660 & 0.896 & 1.494 \\
\hline & Sub-base layer bottom $(0.75 \mathrm{~m})$ & 1.046 & 1.333 & 1.729 & 2.324 & 3.400 \\
\hline \multirow{3}{*}{ Structure III } & Lower surface layer bottom $(0.18 \mathrm{~m})$ & 0.329 & 0.364 & 0.410 & 0.487 & 0.710 \\
\hline & Lower base layer bottom $(0.58 \mathrm{~m})$ & 0.538 & 0.645 & 0.790 & 1.019 & 1.485 \\
\hline & Sub-base layer bottom $(0.98 \mathrm{~m})$ & 1.100 & 1.385 & 1.785 & 2.391 & 3.492 \\
\hline
\end{tabular}

Table 7. Envelope area of stress transfer path (unit: $\mathrm{cm}^{2}$ ).

\begin{tabular}{|c|c|c|c|c|c|c|}
\hline Structural Type & Layer & $50 \%$ & $40 \%$ & $30 \%$ & $20 \%$ & $10 \%$ \\
\hline \multirow{3}{*}{ Structure I } & Lower surface layer bottom $(0.13 \mathrm{~m})$ & 776.4 & 823.2 & 892.1 & 1037.7 & 1561.6 \\
\hline & Lower base layer bottom $(0.51 \mathrm{~m})$ & 3494.5 & 4189.5 & 5266.8 & 7269.4 & $12,129.6$ \\
\hline & Sub-base layer bottom $(0.89 \mathrm{~m})$ & 6324.7 & 8016.1 & $10,472.8$ & $14,440.0$ & $22,097.0$ \\
\hline \multirow{3}{*}{ Structure II } & Lower surface layer bottom $(0.13 \mathrm{~m})$ & 713.9 & 739.8 & 772.5 & 827.6 & 1033.8 \\
\hline & Lower base layer bottom $(0.37 \mathrm{~m})$ & 1748.2 & 2001.1 & 2371.2 & 3039.4 & 4855.2 \\
\hline & Sub-base layer bottom $(0.75 \mathrm{~m})$ & 5667.7 & 7083.2 & 9078.2 & $12,236.0$ & $18,597.2$ \\
\hline \multirow{3}{*}{ Structure III } & Lower surface layer bottom $(0.18 \mathrm{~m})$ & 1071.5 & 1133.7 & 1216.9 & 1356.6 & 1757.3 \\
\hline & Lower base layer bottom $(0.58 \mathrm{~m})$ & 3468.0 & 4034.4 & 4799.2 & 6025.6 & 8780.0 \\
\hline & Sub-base layer bottom $(0.98 \mathrm{~m})$ & 6552.0 & 8120.0 & $10,300.0$ & $13,640.0$ & $19,908.0$ \\
\hline
\end{tabular}

Therefore, the envelope area of each layer was divided by the thickness to get the equivalent envelope area. The equivalent envelope area could characterize the ability of the material to bear and transfer stress per unit thickness in the whole pavement structure. The larger the value, the higher the material utilization efficiency, the more uniform the stress distribution, and the more reasonable the pavement structure. The equivalent envelope area is shown in Table 8. 


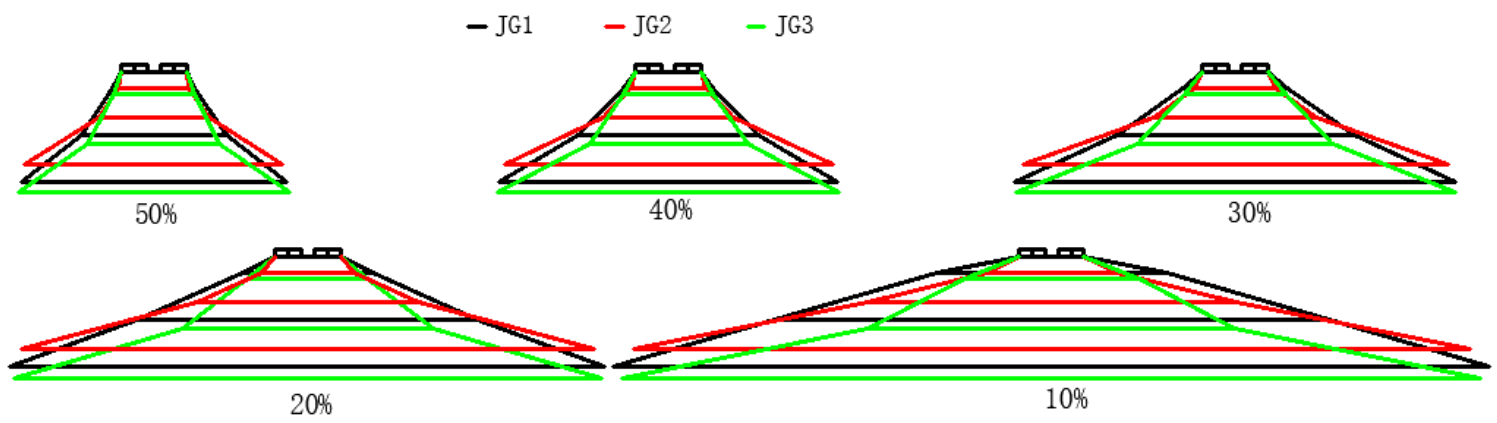

Figure 8. Envelope of transfer path under different thresholds of the three pavement structures.

Table 8. Equivalent envelope area (unit: $\mathrm{cm}^{2}$ ).

\begin{tabular}{|c|c|c|c|c|c|c|}
\hline Structural Type & Layer & $50 \%$ & $40 \%$ & $30 \%$ & $20 \%$ & $10 \%$ \\
\hline \multirow{3}{*}{ Structure I } & Lower surface layer bottom $(0.13 \mathrm{~m})$ & 59.7 & 63.3 & 68.6 & 79.8 & 120.1 \\
\hline & Lower base layer bottom $(0.51 \mathrm{~m})$ & 92.0 & 110.3 & 138.6 & 191.3 & 319.2 \\
\hline & Sub-base layer bottom $(0.89 \mathrm{~m})$ & 166.4 & 211.0 & 275.6 & 380.0 & 581.5 \\
\hline \multirow{3}{*}{ Structure II } & Lower surface layer bottom $(0.13 \mathrm{~m})$ & 54.9 & 56.9 & 59.4 & 63.7 & 79.5 \\
\hline & Lower base layer bottom $(0.37 \mathrm{~m})$ & 72.8 & 83.4 & 98.8 & 126.6 & 202.3 \\
\hline & Sub-base layer bottom $(0.75 \mathrm{~m})$ & 149.2 & 186.4 & 238.9 & 322.0 & 489.4 \\
\hline \multirow{3}{*}{ Structure III } & Lower surface layer bottom $(0.18 \mathrm{~m})$ & 59.5 & 63.0 & 67.6 & 75.4 & 97.6 \\
\hline & Lower base layer bottom $(0.58 \mathrm{~m})$ & 86.7 & 100.9 & 120.0 & 150.6 & 219.5 \\
\hline & Sub-base layer bottom $(0.98 \mathrm{~m})$ & 163.8 & 203.0 & 257.5 & 341.0 & 497.7 \\
\hline
\end{tabular}

As seen in Table 8, the following conclusions were made:

(1) The order of equivalent envelope area of the asphalt layer, base layer, sub-base layer, and pavement structure under the five threshold levels was structure I > structure III > structure II, and the order was not affected by the threshold level.

(2) The material and thickness of the asphalt layer of structure I and structure II were identical, but the equivalent envelope area for structure I was greater than that for structure II. This indicated that the utilization efficiency of structure I asphalt layer was better when compared to structure II. The semi-rigid sub-base materials of the three structures were identical, and the equivalent envelope area followed the order structure I > structure III $>$ structure II. This showed that the utilization efficiency of the semi-rigid sub-base materials followed the order structure I $>$ structure III > structure II. By combining the ranking results of the equivalent envelope area of each structural layer, it can be concluded that the design of structure layer material is the most reasonable for structure I, is slightly worse for structure III, and is the worst for structure II. The rigidity of structure II is the best, but the material utilization efficiency is the lowest. It is not wise to ignore the reasonable allocation of materials in each structural layer in order to pursue the rigidity of the structure; thus, structure II is not an optimum design.

\section{Rationality Analysis of the Equivalent Envelope Area}

Whether the parameter design of the structural materials of an asphalt pavement is optimized is shown by the service performance of the asphalt pavement. Therefore, use of equivalent envelope area to quantitatively evaluate whether the parameter design of asphalt pavement structural materials is optimized can be verified from the following two aspects: (1) whether the relationship between the fatigue life calculated by theory and the value of equivalent envelope area is consistent; and (2) upon tracking and observing the service performance of the test road, whether the relationship between the severity of road distress development and the value of equivalent envelope area is consistent. 


\subsection{Verification by the Fatigue Life}

The fatigue life of three types of asphalt pavement structures was calculated according to the Chinese specifications $[27,28]$.

(1) Fatigue life of the asphalt layer

The bottoms of the asphalt layers of three types of structures were subjected to compressive stress, and hence, the fatigue life could not be taken as a control index.

(2) Calculation of fatigue life based on the deflection value of pavement surface

According to the relationship between the deflection value and the fatigue life in the specifications [29,30],

$$
1_{\mathrm{d}}=600 \mathrm{~N}_{\mathrm{e}}^{-0.2} \mathrm{~A}_{\mathrm{C}} \mathrm{A}_{\mathrm{S}} \mathrm{A}_{\mathrm{b}}
$$

where $1_{d}$ is the design deflection value, and $A_{C}, A_{S}$, and $A_{b}$ are the highway grade coefficient, the surface layer type coefficient, and the pavement structure type coefficient, respectively. Based on the reference specifications, the three coefficients were taken as $1 . \mathrm{N}_{\mathrm{e}}$ is the cumulative equivalent axle number of a lane within the design life. Equation (4) can be converted to $l_{d}=600 \mathrm{~N}_{\mathrm{e}}^{-0.2}$, or $\mathrm{N}_{\mathrm{e}}=\left(\frac{600}{l_{\mathrm{d}}}\right)^{5}$. The ultimate cumulative equivalent axle number was calculated based on the deflection value of structure I, structure II, and structure III and was found to be $2.24 \times 10^{17}$ (times/lane), $2.37 \times 10^{17}$ (times/lane), and $6.82 \times 10^{16}$ (times/lane), respectively. The ultimate cumulative equivalent axle number followed the order structure II > structure I > structure III.

(3) Calculation of the fatigue life of the base and sub-base layers

According to the relationship between the tensile stress and the fatigue life of the base in the specification [31,32],

$$
\begin{gathered}
\sigma_{\mathrm{R}}=\frac{\sigma_{\mathrm{S}}}{\mathrm{K}_{\mathrm{S}}} \\
\mathrm{K}_{\mathrm{S}}=0.35 \mathrm{~N}_{\mathrm{e}}^{0.11} / \mathrm{A}_{\mathrm{C}} \\
\sigma_{\mathrm{R}}=\frac{\sigma_{\mathrm{S}} \times \mathrm{A}_{\mathrm{C}}}{0.11 \mathrm{~N}_{\mathrm{e}}^{0.11}}=\frac{\sigma_{\mathrm{S}}}{0.11 \mathrm{~N}_{\mathrm{e}}^{0.11}} \\
\mathrm{~N}_{\mathrm{e}}=\mathrm{e}^{\frac{1}{0.11} \times \ln \frac{\sigma_{\mathrm{S}}}{0.35 \times \sigma_{\mathrm{R}}}}
\end{gathered}
$$

where $\sigma_{R}$ is the maximum tensile stress of the pavement's structural material layer, and $\sigma_{S}$ is the ultimate splitting strength. In the three structures, the splitting strength $\sigma_{S}$ of the semi-rigid base material is $0.6 \mathrm{MPa}$, and the splitting strength of roller compacted concrete base material is typically 1.0 MPa. $K_{S}$ is the coefficient of the tensile strength of the structure, and $A_{C}$ is the coefficient to represent highway grade. In this paper, the value of $\mathrm{A}_{C}$ was taken as 1.0. The physical meaning of each parameter is shown in Specifications for Design of Highway Asphalt Pavement. The value of the maximum tensile stress $\sigma_{R}$ of the base course is shown in Table 4 . The fatigue life calculation results are shown in Table 9.

Table 9. Fatigue life of the three pavement structures (unit: times/lane).

\begin{tabular}{cccc}
\hline Type & Structure I & Structure II & Structure III \\
\hline Fatigue life of base course & $1.97 \times 10^{14}$ & $3.35 \times 10^{10}$ & $1.91 \times 10^{12}$ \\
Fatigue life of sub-base & $2.24 \times 10^{12}$ & $1.13 \times 10^{12}$ & $8.80 \times 10^{10}$ \\
\hline
\end{tabular}

Table 9 shows that the fatigue life obtained from the back calculation of deflection value (Equation (4)) was significantly greater than that obtained from the back calculation of the tensile stress 
at the bottom of the base layer (Equation (8)). According to the calculation method of fatigue life as per the 06 Specifications of China, the minimum of the two values was taken, and the order of fatigue life of the three structures was structure I $\left(2.24 \times 10^{12}\right)>$ structure III $\left(8.80 \times 10^{10}\right)>$ structure II $\left(3.35 \times 10^{10}\right)$. The fatigue life of structure I was two orders greater than that of structure II and structure III. As seen in Tables 8 and 9, the ranking result of fatigue life of the three structures was consistent with the ranking result of equivalent envelope area.

\subsection{Service Performance of a Test Road}

The test road was opened to traffic in December 2012 and has been open to traffic for seven years. Pavement damage was monitored in 2016-2019 and is shown in Table 10. Under the traffic load, the main distress of the pavement was transverse cracking. The smoothness, rutting, skid resistance, and structural strength were found to be excellent.

Table 10. Cumulative values of transverse fractures of different structures for four years (unit: $\mathrm{m}$ ).

\begin{tabular}{ccccc}
\hline Structure Type & $\mathbf{2 0 1 6}$ & $\mathbf{2 0 1 7}$ & $\mathbf{2 0 1 8}$ & $\mathbf{2 0 1 9}$ \\
\hline Structure I & 3.86 & 10.45 & 12.11 & 14.58 \\
Structure II & 55.7 & 95.77 & 99.06 & 196.52 \\
Structure III & 7.53 & 16.95 & 13.35 & 72.83 \\
\hline
\end{tabular}

According to Table 10, the cumulative value of transverse cracks for four years was in the order of structure I < structure III < structure II. The distress development results from the four-year tracking observation of the test road are consistent with the ranking results of the equivalent envelope area, as shown in Section 4.4, but are inconsistent with the ranking results of the deflection sensitivity. This indicated that the deflection cannot indicate cracking damage. Therefore, the structure layer should be reasonably designed by considering higher material utilization efficiency in order to achieve the best pavement performance.

\section{Discussion}

\subsection{Index Characteristics}

In addition to indicate the nature of deflection, deflection sensitivity also overcame the limitation that different conclusions appeared with different loading forms in the evaluation of deflection value. Stress sensitivity at the bottom of the layer focused on the feedback mechanism of each structural layer under the most unfavorable mechanical response state of the structure from the perspective of materials. The equivalent envelope area overcame the limitation of the traditional method that the thickness of the structural layer was inconsistent with the stress sensitivity. The equivalent envelope area could characterize the ability and utilization of pavement materials to bear and transfer stress per unit thickness.

Sensitivity and equivalent envelope area are indexes for comparison and selection, and should be used together; it is meaningless to use them alone.

\subsection{Analysis of the Inconsistency of Evaluation Results}

Under the double circle uniform load, the evaluation results of deflection sensitivity (structure II $>$ structure I > structure III) were not consistent with the evaluation results of stress sensitivity and equivalent envelope area (structure I > structure III > structure II). Combined with the observation on the test road, it was shown that deflection and deflection sensitivity represented the overall rigidity of the structure but could not indicate about the cracking failure. Therefore, a single stress index of each structural layer could not reflect the interaction among structural layers. 
The equivalent envelope area index served as the further optimization of the sensitivity index. When evaluating the interaction among different layers of an asphalt pavement structure, the equivalent envelope area served as the main index, and the sensitivity index worked as a reference.

\subsection{Structural Design Process}

According to the equivalent envelope area, this study evaluated the coordination in the material design of different structural layers of an asphalt pavement structure. The equivalent envelope area method could be used to distinguish the coordination of different structural material designs. After the structural form of the pavement was designed, the material parameters of the structural layers could be further optimized by using this index according to the design requirements of the pavement.

In the structural optimization design of asphalt pavement, the parameters of structural layer materials should be adjusted according to the utilization of structural layer materials. However, due to the lack of indicators to evaluate whether the design of structural layer materials is coordinated, the direction of pavement structural optimization is not clear. Pavement design usually follows the design process in the specifications, which specify two main steps, namely the primary selection of different pavement structures, and target optimization according to material parameters. The design of pavement structure is performed according to the process shown in Figure 9, and the main processes include the following:

(1) Input parameters: according to the traffic parameters, load level, temperature and humidity conditions, and soil foundation conditions, several alternative forms of asphalt pavement structure and the thickness of each structural layer are preliminarily proposed. The acquisition methods of traffic parameters, load level, temperature and humidity conditions, and soil foundation conditions are implemented in accordance with the specifications.

(2) Primary selection of the structure: according to the equivalent envelope area of each structural layer, the alternative asphalt pavement structure is compared and selected, and the pavement structure with the highest material utilization efficiency is selected.

(3) Preliminary checking of structure: the mechanical response value of each design index is calculated by the theoretical program of a multi-layer elastic system, and the checking of the pavement structure is calculated according to the requirements of the specification until the preliminary structural scheme meets the desired conditions.

(4) Structural optimization: further optimize the structural layer material parameters of the preliminary structural scheme, compare the equivalent envelope area of each structural layer before and after adjustment, observe the variation in stress transfer path and transfer path envelope, and select the structural scheme with the highest material utilization efficiency.

(5) Structural rechecking calculation: the mechanical response value of each design index is calculated by the multi-layer elastic system theoretical program, and the optimized pavement structure is checked according to the specification requirements.

(6) If the requirements are met, the structural design process is completed; if the requirements are not met, repeat steps (4) and (5) until the requirements are met. 


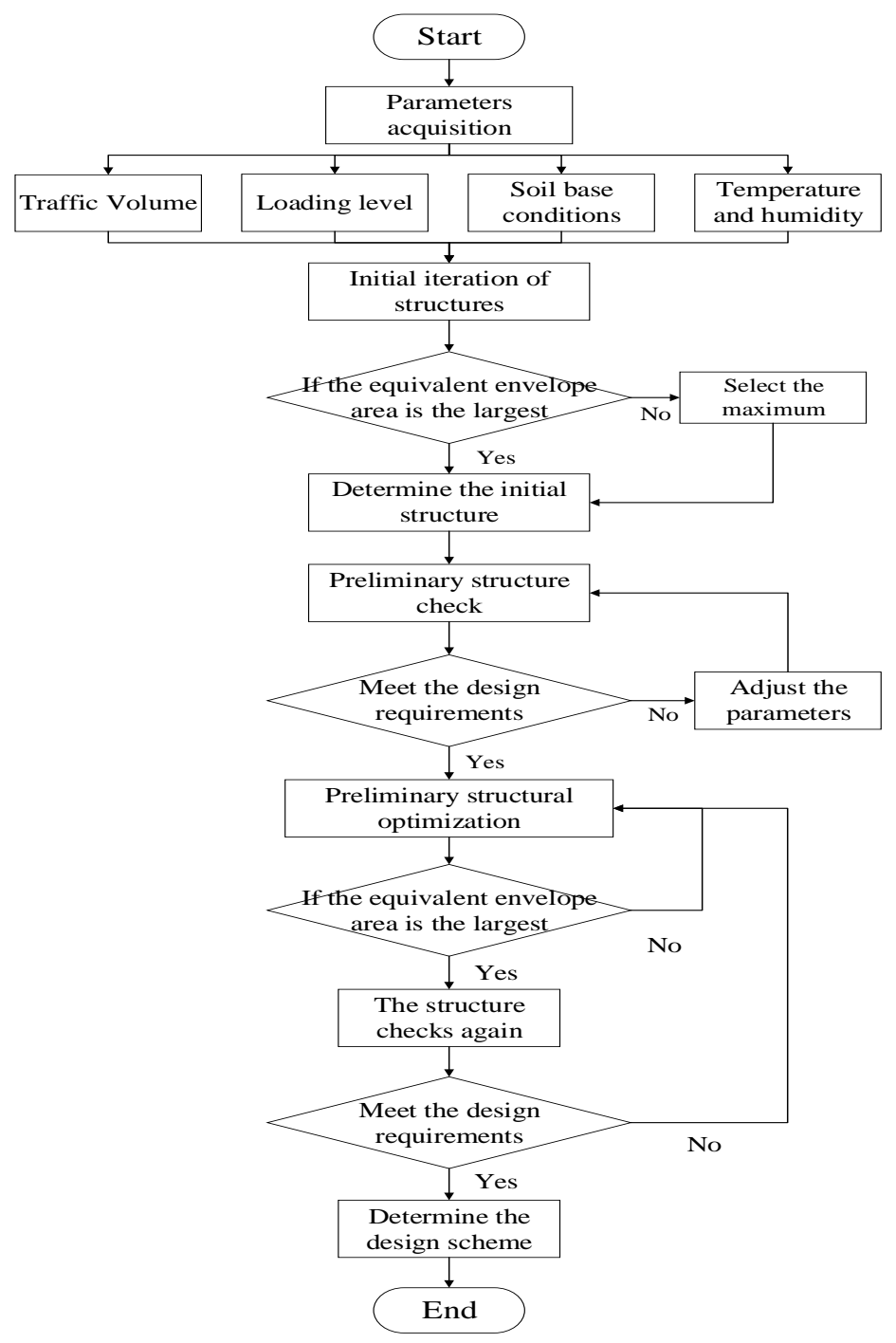

Figure 9. Flowchart of pavement structure design.

\section{Conclusions}

(1) Based on the qualitative analysis of the sensitivity of mechanical response index, this paper proposes a method of quantitative evaluation for the coordination of the material design of asphalt pavement structural layers. The method is primarily based on determining a new index called equivalent envelope area. The larger the equivalent envelope area, the higher is the material utilization efficiency, and the more coordinated is the material design of structural layers.

(2) Software was developed for calculating the equivalent envelope area. The output of the software included equivalent envelope area, stress transfer path, and a transfer path envelope diagram. At the time of quantifying the index, the material workspace and mechanical transfer behavior were visualized, and the differences between different pavement structures were clearly presented. Therefore, the proposed method sets a clear direction for structural optimization design.

(3) Compared to the existing design process, two new steps are added: the comparison and selection of different pavement structural forms and the optimization of structural forms aiming at the coordination of material parameters. A complete design process for the structure design was proposed.

(4) The calculation results of fatigue life were consistent with the data observed in a test road for four years and with the evaluation results obtained by using the equivalent envelope area. 
This consistency showed that the evaluation of the coordination of asphalt pavement structural material design by using the equivalent envelope area is feasible and credible.

Author Contributions: Conceptualization H.L. and N.F.; methodology, H.L. and N.F.; formal analysis, N.F. and Y.F.; investigation, X.W. and Y.F.; resources N.F.; data curation, H.L. and X.W.; writing-original draft preparation, H.L. and X.W.; writing-review and editing, H.L., N.F., X.W., and C.W.; visualization, H.L., N.F., X.W., and C.W.; supervision C.W.; funding acquisition Y.F. All authors have read and agreed to the published version of the manuscript.

Funding: This research was funded by Construction of Science and Technology Projects by the Ministry of Communications of China (2018-MS2-042), the Guangdong Province Transportation Science and Technology Project of China (2012-02-011) and the Foshan City Transportation Science and Technology Project of China (2018AB003841).

Conflicts of Interest: The authors declare no conflicts of interest.

\section{References}

1. AASHTO. Mechanistic-Empirical Pavement Design Guide; AASHTO: Washington, DC, USA, 2008.

2. AI. Thickness Design-Asphalt Pavements for Highways \& Stress; Manual Series; Asphalt Institute: Lexington, KY, USA, 1991.

3. SHELL. Shell Pavement Design Manual-Asphalt Pavements and Overlays for Road Traffic; Shell International Petroleum: London, UK, 1978.

4. Ministry of Communications of the People's Republic of China. Specifications for Design of Highway Asphalt Pavement (JTG D50-2017); China Communications Press: Beijing, China, 2017.

5. Islam, M.R.; Tarefder, R.A. Developing Temperature-Induced Fatigue Model of Asphalt Concrete for Better Prediction of Alligator Cracking. J. Mater. Civ. Eng. 2016, 28, 04015193. [CrossRef]

6. Hussan, S.; Kamal, M.A.; Hafeez, I. Modeling and Correlating Rut Depth Observed in Different Asphalt Mixture Performance Tests. Mehran Univ. Res. J. Eng. Technol. 2018, 37, 537-553. [CrossRef]

7. Bakhshi, B.; Arabani, M. Numerical Evaluation of Rutting in Rubberized Asphalt Mixture Using Finite Element Modeling Based on Experimental Viscoelastic Properties. J. Mater. Civ. Eng. 2018, 30, 04018088. [CrossRef]

8. Kim, J.; Koh, C. Development of a Predictive System for Estimating Fatigue Life of Asphalt Mixtures Using the Indirect Tensile Test. J. Transp. Eng. 2012, 138, 1530-1540. [CrossRef]

9. Al-Khateeb, G.G.; Ghuzlan, K.A. The combined effect of loading frequency, temperature and stress level on the fatigue life of asphalt paving mixtures using the IDT test configuration. Int. J. Fatigue 2014, 59, 254-261. [CrossRef]

10. Mansourkhaki, A.; Samdzadeh, A.; Jebalbarezi, M. Study of loading waveform, loading duration, rest period and stress level on fatigue life of asphalt mixtures. Eng. Solid Mech. 2015, 3, 93-102. [CrossRef]

11. Zhu, G.J.; Wu, S.P.; Liu, R.; Zhou, L. Study on the Fatigue Property for Aged Asphalt Mixtures by Using Four Point Bending Tests. Mater. Sci. Forum 2009, 614, 289-294. [CrossRef]

12. Pais, J.C.; Fontes, L.P.; Pereira, P.A.; Minhoto, M.J.; Kumar, D.S.; Silva, B.T. Analysis of the variation in the fatigue life through four-point bending tests. In Proceedings of the C-TAC—Comunicações a Conferências Internacionais; Universidade do Minho: Braga, Portugal, 2009.

13. Montazeri, S. Assessing Repeatability of Four-Point Bending Method for Estimating Fatigue Cracking of Hot Mix Asphalt. Master's Thesis, University of Texas at El Paso, El Paso, TX, USA, January 2009.

14. Wang, Y.D.; Keshavarzi, B.; Kim, Y.R. Fatigue Performance Analysis of Pavements with RAP Using Viscoelastic Continuum Damage Theory. Ksce J. Civ. Eng. 2018, 22, 2118-2125. [CrossRef]

15. Yanhong, Z.; Aiqin, S.; Yun, H. Control and verification of modulus gradient of flexible pavement structural layers. J. Highw. Transp. Res. Dev. 2017, 34, 28-34.

16. Yanhong, Z.; Xiaofan, W. Analysis on mechanical response for three kinds of asphalt pavement under discontinuous interlayer condition. J. Wuhan Univ. Technol. (Transp. Sci. Eng.) 2013, 37, 589-592.

17. Jianlong, Z. New structure design of durable asphalt pavement based on life increment. China J. Highw. Transp. 2014, 27, 1-7.

18. St Martin, J.; Harvey, J.T.; Long, F.; Lee, E.B.; Monismith, C.L.; Herritt, K. Long-life rehabilitation design and construction: I-710 freeway, long beach, California. Transp. Res. Circ. 2001, 503, 50. 
19. Harm, E. Illinois Extended-life Hot-Mix Asphalt Pavements. Transp. Res. Circ. 2001, 503, 108-113.

20. Peng, C.; Minhua, S.; Lijun, S. Research on design indices of perpetual asphalt pavement. J. Traffic Transp. Eng. 2008, 8, 37-42.

21. Shutao, M. Study on Reasonable Structure of Asphalt Pavement. Ph.D. Thesis, Southeast University, Dhaka, Bangladesh, 2005.

22. Fuming, L. Study on Damge Behavior and Structural Life Reasonable Matching of Long-Life Asphalt Pavement. Ph.D. Thesis, South China University of Technology, Guangzhou, China, 2010.

23. Songtao, L.; Jianfeng, L.; Aijun, Y.; Jie, C. Matching of fatigue life for asphalt pavement based on deflection and layer bottom tensile stress indexes. J. Chang. Univ. Sci. Technol. (Nat. Sci.) 2014, 11, 8-14.

24. Zhuanyi, Z. Research on Design Index and Parameter of Flexible Base Asphalt Pavement Based on Acceleration Response. Ph.D. Thesis, Changan University, Xi'an, China, 2012.

25. Hao, L.; Feng, L.; Xinquan, X.; Wenwei, W. Research on Inorganic Binders Stabilized Base Asphalt Pavement Structure Calculation Graphic. J. Wuhan Univ. Technol. (Transp. Sci. Eng.) 2018, 42, 334-338.

26. Hao, L.; Xinquan, X.; Feng, L.; Yaobin, G. Comparative analysis of pavement mechanical response of four kinds of contact forms of uniformly-distributed load. J. Chongqing Jiaotong Univ. (Nat. Sci.) 2019, 38, 53-58.

27. Wang, X.C.; Fang, N.R.; Ye, H.Y.; Zhao, J. Fatigue Damage Analysis of Cement-Stabilized Base under Construction Loading. Appl. Sci. 2018, 11, 2263. [CrossRef]

28. Ye, H.Y.; Wang, X.C.; Fang, N.R.; Su, Z.Y. Low-Temperature Performance and Evaluation Index of Gussasphalt for Steel Bridge Decks. Adv. Mater. Sci. Eng. Sci. 2019. [CrossRef]

29. Ma, Y.; Gu, J.; Li, Y.; Li, Y. The bending fatigue performance of cement-stabilized aggregate reinforced with polypropylene filament fiber. Constr. Build. Mater. 2015, 83, 230-236. [CrossRef]

30. Wang, X.C.; Su, Z.Y.; Xu, A.M.; Zhou, A.G.; Zhang, H.T. Shear fatigue between asphalt pavement layers and its application in design. Constr. Build. Mater. Sci. 2017, 135, 297-305. [CrossRef]

31. Lim, S.; Zollinger, D. Estimation of the compressive strength and modulus of elasticity of cement treated aggregate base materials. Transp. Res. Rec. 2003, 1837, 30-38. [CrossRef]

32. Fang, N.R.; Wang, X.C.; Ye, H.Y.; Sun, Y.N. Study on Fatigue characteristics and interlayer design method of waterproof cohesive bridge deck layer. Appl. Sci. 2019, 9, 2090. [CrossRef]

(C) 2020 by the authors. Licensee MDPI, Basel, Switzerland. This article is an open access article distributed under the terms and conditions of the Creative Commons Attribution (CC BY) license (http://creativecommons.org/licenses/by/4.0/). 